\title{
MIKE 3 versus HARTMANN apparatus: Comparison of measured minimum ignition energy (MIE)
}

\section{Corresponding author:}

A. JANES (INERIS - Parc ALATA BP 2 - 60550 Verneuil-en-Halatte - tel: + 33

344556142 - Fax: + 33344556200 - mail: agnes.janes@ineris.fr)

\section{Authors:}

A. JANES - J. CHAINEAUX - D. CARSON - P.A. LE LORE

\begin{abstract}
:
In this study, MIE values measured with two different explosion tubes, HARTMANN and MIKE 3, are compared.

Generally, MIKE 3 apparatus provides MIE results which are equal or lower to those measured with the HARTMANN apparatus; this is particularly true for the energy ranges between 1 and $10 \mathrm{~mJ}$ and higher than $100 \mathrm{~mJ}$.

Differences observed can modify samples classification according to their sensitivity to electrostatic ignition sources.

Nevertheless, ignition of a dust cloud by an electrostatic discharge is complex, and implies a different mechanism from that occurring during MIE tests. Thus, it seems difficult to synchronise dust dispersion and spark triggering to obtain optimal concentration in the spark area. Moreover, spark characteristics such as duration or energy feeding rate of spark can not reproduce exactly industrialworld ones. On this point, it is not possibly to conclude if characteristics of MIKE 3 electric circuit, e.g. resistance and inductance, are more relevant than HARTMANN circuit ones.
\end{abstract}

Key words:

Minimum ignition energy - HARTMANN apparatus - MIKE 3 apparatus explosion tube - electrostatic ignition - spark 


\section{INTRODUCTION}

Prevention of dust explosion in industries manufacturing or handling combustible powder or dust is a major challenge [1] and [2]. Minimum ignition energy (MIE) determination of dust/air mixtures is useful for risk assessment, since MIE value is linked to the sensitivity of a sample to be ignited by an electrostatic source. But does experimental determination of MIE in explosion tubes such it is presently proposed in standards, using different apparatuses, conduce to the same results. In this paper, MIE values measured with two different explosion tubes, HARTMANN and MIKE 3, are compared and discussed.

\subsection{Principle of MIE OF DUST/AIR MIXTURE DETERMINATION}

MIE of a combustible dust cloud is the lowest energy that is sufficient to ignite a dust-air mixture, under specified test conditions.

The determination of the MIE requires pneumatically dispersing of a given amount of dust in a test chamber. An electric spark of a theoretical energy level is then triggered between two electrodes located inside the chamber, which is an open transparent tube. Then, the diagnosis of the ignition is visual: propagation or non-propagation of a flame inside the tube. Standards also allowed implementing pressure-based detection instead of this visual detection in a closed system.

The main influencing factors on MIE recorded values, for a given dust, are:

- (1) delay between dust dispersion and sparkover,

- (2) dispersion method, influenced e.g. by the nozzle size and shape,

- (3) spark characteristics e.g. duration and energy, influenced by electric circuit design such as including capacity, inductance and resistance values,

- (4) amount of dust and particle distribution placed in the bottom cup of the explosion chamber prior to the test.

The two first items influence turbulence, dust concentration and particle distribution in the gap between electrodes at the time of sparkover. The third 
point is linked to the level of energy needed to ignite combustion. Finally, the last item influences average dust concentration and particle distribution in the explosion tube.

The MIE is the energy initially stored in the electric circuit that is just sufficient to cause the ignition of the dust/air suspension, under the optimum conditions of delay between dust dispersion and sparkover and dust concentration.

\subsection{StUdY CONTEXT AND OBJECTIVE}

Before INERIS acquired in 2002 a MIKE 3 apparatus [3], MIE tests were carried out with a HARTMANN tube built by CERCHAR in accordance with a standard published by the International Electrotechnical Commission (IEC) [4].

After giving details about the two applicable standards and the two apparatuses operated, this paper comments results of comparative experiments on HARTMANN and MIKE 3 explosion tubes.

\subsection{ApPlicable STANDARDS}

The two reference standards for MIE determination of dust/air mixtures applied in this study are IEC 61241-2-3 [4], applied to HARTMANN apparatus, and EN 13821 [5], applied to MIKE 3 explosion tube. Major differences between these two references are shortly discussed below.

Several convenient spark-generating systems are listed in both standards (Table 1).

Standard IEC 1241-2-3 [4] does not specify any constraint related to the dust dispersion system. On the contrary, the standard EN 13821 [5] specifies that dust dispersion must be triggered by an air blast powered at 7 bar. These differences in dust dispersion systems will necessary induce effects on turbulence in the tube and on dust concentration and particle distribution into spark area.

According to EN 13821 [5], a non-ignition result must be recorded if the cloud does not ignite after only 10 successive attempts, whereas IEC 1241-2-3 [4] requires 20 successive unsuccessful ignition attempts to record a non-ignition 
result. This may have an influence on the result of a MIE test, especially because of the two following aspects:

- multiplication of successive attempts without removing dust, cleaning the tube and recharging it with a new sample can modify particle distribution of friable dust or hygrometry of very hygroscopic samples, e.g. corn starch. Moreover, successive attempts will disperse a fraction of sample outside the test chamber,

- ignition by an electrostatic discharge, such as occurring in explosion tube during MIE tests, is a stochastic phenomenon. So, the less attempts are done, the more uncertainties are associate to the test result.

\subsection{USUAL INTERPRETATION OF MIE RESULTS}

Usually, MIE results are referred to electrostatic ignition risk assessment. It is established that MIE is representative of the sensitivity of a sample to be ignited by an electrostatic source. In the same way, the comparison of MIE results indicates the relative sensitivity of samples.

Nevertheless, ignition of a dust cloud by an electrostatic phenomenon is complex and differs from the test mechanism. This is due to the difficulty to quantify and reproduce experimentally real-world spark characteristics and especially spark duration and synchronisation between dust dispersion and sparkover [6] - [10] (see discussion in section 3.2). However, it is not possible to accurately qualify the ignition sensitivity of a sample according to the test result.

The recommendations for interpreting MIE results are based on energy levels available on MIKE 3 apparatus. According to the INERIS usual practice, MIE can be ranked as follow:

- MIE > $1000 \mathrm{~mJ}$ : sample almost insensitive to electrostatic ignition,

- $300 \mathrm{~mJ}<\mathrm{MIE}<1000 \mathrm{~mJ}, 100 \mathrm{~mJ}<\mathrm{MIE}<300 \mathrm{~mJ}$ and $30 \mathrm{~mJ}<\mathrm{MIE}<$ $100 \mathrm{~mJ}$ : sample sensitive to electrostatic ignition, 
- $10 \mathrm{~mJ}<\mathrm{MIE}<30 \mathrm{~mJ}$ and $3 \mathrm{~mJ}<\mathrm{MIE}<10 \mathrm{~mJ}$ : sample very sensitive to electrostatic ignition,

- $1 \mathrm{~mJ}<\mathrm{MIE}<3 \mathrm{~mJ}$ and $\mathrm{MIE}<1 \mathrm{~mJ}$ : sample extremely sensitive to electrostatic ignition.

\section{EXPERIMENTAL}

\subsection{HARTMANN APPARATUS}

HARTMANN apparatus was designed and manufactured by CERCHAR in the seventies. This equipment was systematically employed for measuring the MIE of dust/air mixtures until its progressive take over by the MIKE 3 apparatus until the end of 2004.

Dust dispersion and ignition take place in $1.6 \mathrm{~L}$ Plexiglas tube open at the top. The diameter of the explosion chamber is $71 \mathrm{~mm}$ and the height $420 \mathrm{~mm}$. The dust placed in the bottom cup prior to the test is dispersed by two successive air blasts powered with a mushroom shaped nozzle at 450 mbars (pre-rising) and then 500 mbars (dispersing), in order to generate an homogeneous cloud. Fig. 1 shows the low bottom cup of the HARTMANN apparatus on the top, of which the Plexiglas tube is settled.

Our HARTMANN apparatus exhibits only one electric circuit. The spark is triggered by a transformer and this circuit operate a two-electrode system. More details are given in the A6 appendix of EN 13821 standard [5] as well as in the A5 appendix of the IEC 1241-2-3 [4] standard (Table 1). The gap between the tapered tips of the stainless steel electrodes (diameter: $2.4 \mathrm{~mm}$ ) is $6 \mathrm{~mm}$.

The available energy values $(\mathrm{mJ})$ are chosen among: $1200 ; 810 ; 540 ; 360$; $225 ; 158 ; 105 ; 77 ; 58 ; 45 ; 36 ; 27 ; 21 ; 16 ; 12 ; 9.4 ; 7.6 ; 5.9$ and 4.5. Due to a breakdown that occurred during the course of the study, the $1200 \mathrm{~mJ}$ condenser was replaced. Delivered energy is now close to $1100 \mathrm{~mJ}$.

The inductance of the circuit of our HARTMANN explosion tube is not adjustable: a value of $570 \mathrm{mH}$ was measured. 
The delay between the second air blast and the triggering of the spark can be selected as follow (in seconds): $0.3 ; 0.35 ; 0.4 ; 0.45 ; 0.5 ; 0.6 ; 0.7 ; 0.8$; 0.9 and 1 . Fig. 2 shows the control and operation interface of our HARTMANN apparatus.

\subsection{MIKE 3 APPARATUS}

The MIKE 3 apparatus was acquired from the KUHNER Company [3].

The dispersion and ignition occur in a 1,2 $\mathrm{L}$ glass tube. A removable vent is located at the top of the tube. The diameter of the explosion chamber is $68.5 \mathrm{~mm}$ and the height $315 \mathrm{~mm}$. The dust is dispersed by an air blast with a mushroom shaped nozzle, at the pressure of 7 bar. As for the HARTMANN explosion tube, the gap between the tapered tips of the stainless steel electrodes (diameter: $2.0 \mathrm{~mm}$ ) is $6 \mathrm{~mm}$. However, when using the method of triggering by electrode movement, the electrode gap cannot be known at the time of sparkover.

MIKE 3 can operate with one of the following circuits (Table 1):

- triggering by high-voltage relay, using a two-electrode system. This circuit is employed for low energies ( 1 and $3 \mathrm{~mJ}$ ). It is described more precisely in the A2 appendix of the EN 13821 standard [5],

- triggering by electrode movement, using a two-electrode system. This circuit is operated for high energies $(10,30,100,300$ and $1000 \mathrm{~mJ})$. It is described in details in the A3 appendix of the EN 13821 standard [5] and in the A3 annex of the IEC 1241-2-3 standard [4].

The inductance of the electric circuit is adjustable to either 0 or $1 \mathrm{mH}$.

The usual delays between dust dispersion and sparkover vary from $60 \mathrm{~ms}$ to $180 \mathrm{~ms}$, by $30 \mathrm{~ms}$ time steps. 


\subsection{PROCEDURE}

\subsubsection{TEST PROCEDURE}

Each series of tests is carried out for a given concentration of dust in air and a given delay between dust dispersion and sparkover.

In order not to sidestep the issue of this study, for both HARTMANN (IEC 61241-2-3) and MIKE 3 (EN 13821) test procedures, 10 successive unsuccessful ignition attempts to record a non-ignition result were required. Moreover, dust was removed after a maximum number of five non-ignition attempts and a new sample was then prepared for the following attempts.

The tests begin with the highest of ignition energy value (1000 $\mathrm{mJ}$ for MIKE 3 and $1200 \mathrm{~mJ}$ in the case of HARTMANN).

It is also necessary to set a definite value of average dust concentration. The tests begin with an average concentration close to $750 \mathrm{~g} / \mathrm{m}^{3}$.

The delay between dust dispersion and sparkover set for the first series is $120 \mathrm{~ms}$ in the case of MIKE 3 and $300 \mathrm{~ms}$ for HARTMANN.

Lastly, circuit inductance is kept constant during the complete course of the procedure. Tests with MIKE 3 explosion tube were carried out with an inductance of $1 \mathrm{mH}$ only. Some tests were carried out in order to see the influence of the selected inductance value (either 0 or $1 \mathrm{mH}$ ) on results obtained for one sample.

Several series of tests are then conducted in the range of optimal dust cloud concentrations at the available delays between dust dispersion and sparkover (MIKE 3: $60 \mathrm{~ms}$ and $180 \mathrm{~ms}$; HARTMANN: $700 \mathrm{~ms}$ ).

\subsubsection{COMPARISON CRITERION}

According to the EN 13821 standard [5], validation tests must be carried out on at least five different dust type for each three different energy ranges: $1 \mathrm{~mJ}-$ $10 \mathrm{~mJ}, 10 \mathrm{~mJ}-100 \mathrm{~mJ}$ and $100 \mathrm{~mJ}-1 \mathrm{~J}$.

The different dusts to be tested include at least two metal powders, two natural organic powders, two synthetic organic powders and two coal dust. 
With the aim of comparing various equipment, this standard also specifies that only one value of MIE (Es) must be kept, instead of the range of measured energy for witch ignition took place. This Es value is calculated on the basis of a statistical formula given in the standard. Conformity between two apparatuses is proven when Es values for all the dust tested differ by a factor less than 3 .

However, the comparison between HARTMANN and MIKE 3 results was carried out on the basis of the interval defined by minimum and maximum energies for which an ignition is observed. Thus, the value Es was not calculated.

We compared the results obtained with both apparatuses for samples belonging to the three energy ranges ( $1 \mathrm{~mJ}-10 \mathrm{~mJ} ; 10 \mathrm{~mJ}-100 \mathrm{~mJ}$ and $100 \mathrm{~mJ}-1 \mathrm{~J})$. As far as possible, we tried to comply with the minimum number of five samples by energy range as well as with the criterion relating to the type of samples.

\subsection{SAMPLES TESTED}

Selected samples are listed in table 2, where the classification in energy range is based on MIKE 3 results.

\section{RESULTS AND DISCUSSION}

\subsection{COMPARISON OF MIE RESULTS}

Results are presented in table 3. Fig. 4 shows MIE measured values for tested samples with both explosion tubes.

\subsubsection{RANGE FROM 1 TO $10 \mathrm{MJ}$}

Generally, MIKE 3 results are lower than those obtained with the HARTMANN apparatus.

In addition, the criterion of the maximum ratio of 3 between two valid results is only confirmed for the lower limit of the result interval of calcium stearate. 
On the contrary, this criterion is valid in every case with regard to the upper limit, except for niacin (CaRo 051 ${ }^{1}$ [11]. This had also been witnessed during round robin tests carried out in 2003 [12].

\subsubsection{RANGE FROM 10 TO $100 \mathrm{MJ}$}

In general, the range of results obtained with the HARTMANN tube is within the range obtained with the MIKE 3. This can be explained by the available energy levels:

- for the HARTMANN apparatus, seven levels are available between the two levels 12 and $105 \mathrm{~mJ}$ of the range considered,

- for the MIKE 3 apparatus, there is only one level available $(30 \mathrm{~mJ})$ between the two levels 10 and $100 \mathrm{~mJ}$ of the range considered.

In the particular case of one of the agricultural products, the HARTMANN result is significantly higher than that with the MIKE 3.

In all other cases, the criterion of the maximum ratio of 3 between two results can be considered as met.

\subsubsection{RANGE FROM 100 TO $1000 \mathrm{MJ}$}

Only tests carried out with aluminium dust lead to coherent results between the two apparatuses. The HARTMANN result being however higher than that obtained with the MIKE 3.

In three cases, an ignition was observed with the MIKE 3 apparatus whereas there was none with the HARTMANN. Moreover, the criterion of the maximum ratio of 3 between two results was never met.

A doubt remains for two products for which no ignition was observed whatever the apparatus.

\subsubsection{SYNTHESIS}

Table 4 itemizes, for the various samples studied, the sensitivity to electrostatic ignition sources, which can be deducted from MIE determination results.

\footnotetext{
${ }^{1}$ CaRo 05 (pyridine-3-carboxamide) is the reference sample provided for round robin tests
} 
The comparison of the sensitivity to electrostatic ignition sources deducted from the MIE results with both MIKE 3 and HARTMANN apparatuses, highlights the following points:

- in the range of 1 to $10 \mathrm{~mJ}$, operating with MIKE 3 can discriminate "extremely sensitive" from very "sensitive" samples. Indeed, in four out of five cases, samples seen as "extremely sensitive" based on MIKE 3 results were only seen as "very sensitive" according to the HARTMANN results. In only one case out of the five tests carried out with both apparatuses results converged in identifying the sample as "very sensitive",

- in the range of 10 to $100 \mathrm{~mJ}$, ignition sensitivities do not depend on the apparatus employed ("very sensitive" in one case and "sensitive" in five cases). However, one sample which is rated "very sensitive" with the HARTMANN apparatus is only seen as "sensitive" according to the MIKE 3 results,

- in the range of $100 \mathrm{~mJ}$ to $1 \mathrm{~J}$, both HARTMANN and MIKE 3 apparatuses discriminates three different ignition sensitivities. In three out of six cases, an agreement is reached: samples are rated "sensitive" (1 case) or almost "not sensitive" (2 cases), with both apparatuses. However, in three other cases, samples are rated "sensitive" by MIKE 3 results, whereas they are rated almost "not sensitive" by HARTMANN tests.

Round robin tests with CaRo05 (pyridine-3-carboxamide, year 2005), and previously with CaRo03 (pyridine-3-carboxamide, year 2003), showed that MIKE 3 apparatus and the test procedure implemented gave equivalent results than other laboratories.

\subsection{INFLUENT FACTORS ON MIE RESULTS}

Nifuku and Katoh [7] studied the influence of particle size distribution on MIE. Their measurements showed that the smaller the particle size, the smaller the ignition energy, because of the larger specific surface area.

The same authors also reported the influence of dust concentration in the sparkover area [9]. They showed that a condition to forward the ignition inside 
the dust cloud is a sufficient low distance between particles. Thus, the particle concentration into the dust/air suspension has an influence on ignition probability. This is confirmed by the results of the tests carried out in this study. Fig. 5 shows the evolution of MIE with particle concentration for sulphur powder dust on MIKE 3 apparatus.

Nevertheless, Fig. 6, which compares MIE evolution with particle concentration for the same sulphur powder on both MIKE 3 and HARTMANN explosion tubes, shows that the average particle concentration in the tube isn't the only factor to be considered.

Indeed, the method of dust dispersion operated and the delay between dispersion and sparkover are influent on turbulence inside the tube, dust concentration and particle distribution in the spark area. Especially, nozzle size, shape and pressure are very different on MIKE 3 and HARTMANN apparatuses, as same as the range of delay available between dust dispersion and sparkover. Thus, such differences on this combined parameters lead certainly to the gap between optimal concentrations observed on Fig. 6. It is interesting to notice that this gap is not a constant for all the samples tested, as shows Table 5. It is supposed that the influence of these factors depends on the nature and maybe the particle size distribution of the dust, but any simple correlation can be found at this stage.

Randberg and Eckhoff [10] pointed that MIE tests by using independent dust dispersion and spark triggering is not really representative of electrostatic discharges which actually occur inside a dust cloud in industrial situations, because of the difficulty to synchronise sparkover and optimal concentration.

When using a method with a spark triggering by the dust cloud itself, very low MIE (<1 mJ) were measured [10]. Thus, independent dust dispersion and spark triggering, such as carried out in this study, conduce to quite conservative results.

Another influent factor on MIE results is the design of the ignition energy power supply. Nifuku and Katoh [7] showed that the feeding time and the feeding rate of the ignition energy influence considerably the ignition of a dust cloud. This 
was confirmed either by Randberg et al. [18], or by Bennett et al. [8] who demonstrated through a literature review [13]-[17] how adding either a larger inductance or a larger resistance can increase the spark duration and thus decrease the MIE of a given dust. This is confirmed by Fig. 7, on which can be compared MIE results for lycopodium on MIKE 3 apparatus, with and without inductance in electric power supply. Considering these results, it seems than adding an inductance increased the probability of ignition.

In [9], Nifuku and Katoh also pointed that the larger the feeding rate of spark energy, the higher the ignition probability.

\section{CONCLUSION}

The results of this study are concluded as follows.

1. Generally, MIKE 3 apparatus provides MIE results which are equal or lower to those measured with the HARTMANN apparatus; this is particularly true for the energy ranges between 1 and $10 \mathrm{~mJ}$ and higher than $100 \mathrm{~mJ}$. Differences observed can alter samples classification according to their sensitivity to electrostatic ignition sources.

2. According to the results obtained by testing CaRo05 (pyridine-3carboxamide) with both apparatuses, it is tempting to consider that using MIKE 3 explosion tube instead HARTMANN can discriminate more efficiently the ignition sensitivity of dust, and thus support the recommendation of more relevant ignition prevention measures, especially for dust presenting low MIE.

The literature reviewed shows that particle size distribution and dust concentration in the spark area are influent factors on MIE results, as well as method of dust dispersion in the explosion chamber and delay between dispersion and sparkover. These two last points may explain some differences observed between MIKE 3 and HARTMANN apparatuses, but it appears that this gap is not a constant for all samples tested. 


\section{AKNOWLEDGMENTS}

This work was supported financially by the French Ministry of Environment and Durable Development.

\section{REFERENCES}

[1] R.K. Eckhoff, Dust Explosions in the Process Industries, 3rd ed., Gulf Professional Publishing/Elsevier, Boston, 2003

[2] W. Bartknecht, Explosionsschutz, Springer-Verlag, Berlin, 1993

[3] C. Cesana, R. Siwek, MIKE 3. Minimum Ignition Energy, B021_033, Adolf Kühner AG, Birsfelden, Switzerland, 2001

[4] IEC, Electrical apparatus for use in the presence of combustible dust, Part 2: Test methods, Section 3: Method of determining minimum ignition energy of dust/air mixtures, IEC International Standard CEI 61241-2-3, International Electrotechnical Commission, Geneva, 1994

[5] CEN, Potentially explosive atmospheres, Explosion prevention and protection, Determination of minimum ignition energy of dust/air mixtures, European Standard EN 13821, European Committee for Standardization, Brussels, 2003

[6] BOUDALAA M., PROUST C., Energie minimale d'inflammation des nuages de poussières, Méthode de mesure et application aux situations industrielles cas des étincelles électrostatiques, rapport pour le Ministère de l'Aménagement du Territoire et de l'Environnement, Paris, 1996

[7] M. Nifuku, H. Katoh, Incendiary characteristics of electrostatic discharge for dust and gas explosion, J. Loss Prevent. Proc. 14 (2001) 547-551

[8] D. Bennett et al., A test for electrical ignition of flammable dust clouds, J. Loss Prevent. Proc. 16 (2003) 33-40

[9] M. Nifuku, H. Katoh, A study on the static electrification of powders during pneumatic transportation and the ignition of dust cloud, Powder Technology 135-136 (2003) 234-242 
[10] E. Randeberg, R.K. Eckhoff, Measurement of minimum ignition energies of dust clouds in the $<1 \mathrm{~mJ}$ region, Journal of Hazardous Materials 140 (2007) 237-244

[11] C. Cesana, Final Report, Calibration-Round-Robin CaRo 03, B052_185, Adolf Kühner AG, Birsfelden, Switzerland, 2004

[12] C. Cesana, Final Report, Calibration-Round-Robin CaRo 05, B052_205, Adolf Kühner AG, Birsfelden, Switzerland, 2006

[13] S.J. Parker, Electric spark ignition of gases and dusts, PhD Thesis, The City University, London, 1985

[14] D.R. Ballal, Ignition and flame quenching of quiescent dust clouds of solid fuels, Proc. Roy. Soc. Lond., July (1980) 479-500

[15] A.R. Boyle, F.J. Llewellyn, The electrostatic ignitability of dust clouds and powders, J. Soc. Chem. Ind. Trans., 69 (1950) 73-181

[16] T. Matsuda, M. Naito, Effects of spark discharge duration on ignition energy for dust/air suspensions. In J.K. Beddow (Ed.), Particulate systems, technology and fundamentals (p. 189), Hemisphere Publishing Corp/MacGraw Hill, New York, 1983

[17] A. Norberg, D. Xu, D. Zhang, Powder Ignition energy measured utilizing a new fluidized bed ignition chamber, Report ISSN 0349-83 52, Institute of Hight Voltage research, Upplsala, Sweden, 1988

[18] E. Randeberg, W. Olsen, R.K. Eckhoff, Initiation of dust explosions by electric spark discharges triggered by the explosion cloud itself, J. Loss Prevent. Proc. 19 (2006) 154-160 


\begin{tabular}{|c|c|c|c|}
\hline Circuit design & Use in the study & $\begin{array}{c}\text { Reference in CEI } \\
1241-2-3[4]\end{array}$ & $\begin{array}{c}\text { Reference in EN } \\
13821[5]\end{array}$ \\
\hline $\begin{array}{l}\text { Triggering by high-voltage } \\
\text { relay, using a two-electrode } \\
\text { system }\end{array}$ & $\begin{array}{c}\text { MIKE } 3 \text { apparatus for } \\
\text { low energies ( } 1 \text { to } 3 \\
\mathrm{~mJ} \text { ) }\end{array}$ & - & Annex A2 \\
\hline $\begin{array}{l}\text { Triggering by electrode } \\
\text { movement, using a two- } \\
\text { electrode system }\end{array}$ & $\begin{array}{l}\text { MIKE } 3 \text { apparatus for } \\
\text { high energies (10 to } \\
1000 \mathrm{~mJ} \text { ) }\end{array}$ & Annex A3 & Annex A3 \\
\hline $\begin{array}{l}\text { Triggering by auxiliary spark, } \\
\text { using a three-electrode } \\
\text { system }\end{array}$ & Not used & Annex A2 & Annex A4 \\
\hline $\begin{array}{l}\text { Triggering by voltage } \\
\text { increase, using a two- } \\
\text { electrode system }\end{array}$ & Not used & Annex A4 & Annex A5 \\
\hline $\begin{array}{l}\text { Triggering by transformer, } \\
\text { using a two-electrode system }\end{array}$ & $\begin{array}{l}\text { HARTMANN } \\
\text { apparatus }\end{array}$ & Annex A5 & Annex A6 \\
\hline
\end{tabular}

Table 1: Spark-generating systems referred by each explosion tube and standard used. Further details about precise design of these circuits are given in [4] and [5]. 


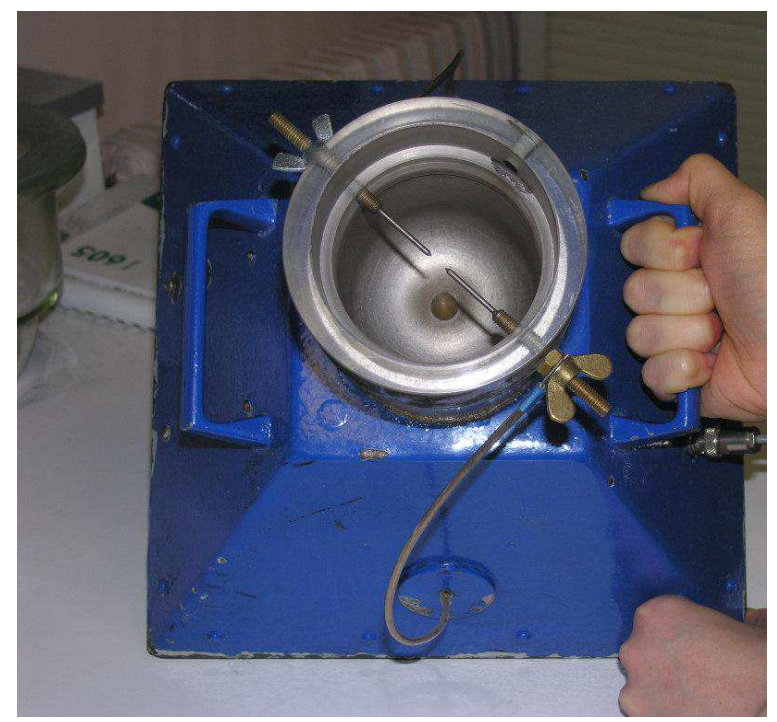

Figure 1: View of the low bottom part of the HARTMANN apparatus (electrodes and dispersion mushroom) on the top of which the Plexiglas tube is settled prior to a test. 


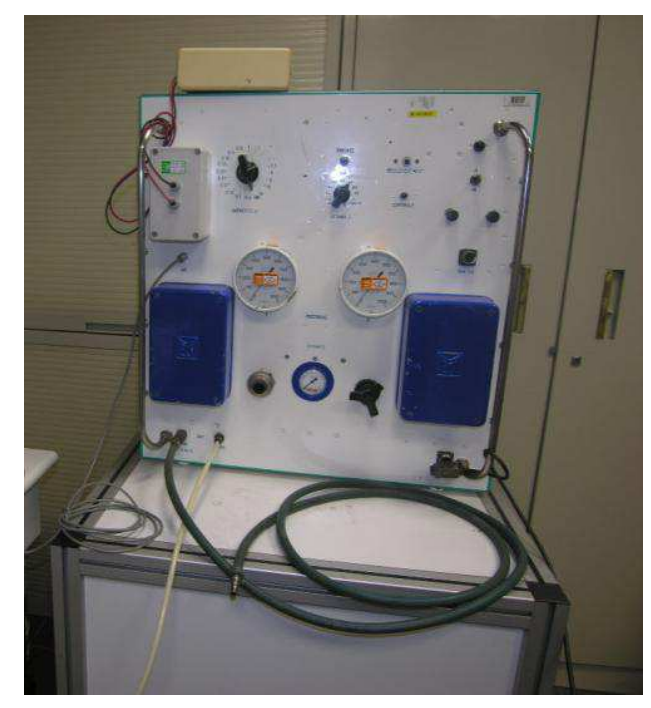

Figure 2: View of the control and operation interface of the HARTMANN apparatus on which can be selected (1) the energy level (by selection of the electric circuit capacity) and (2) the delay between dust dispersion and sparkover. 


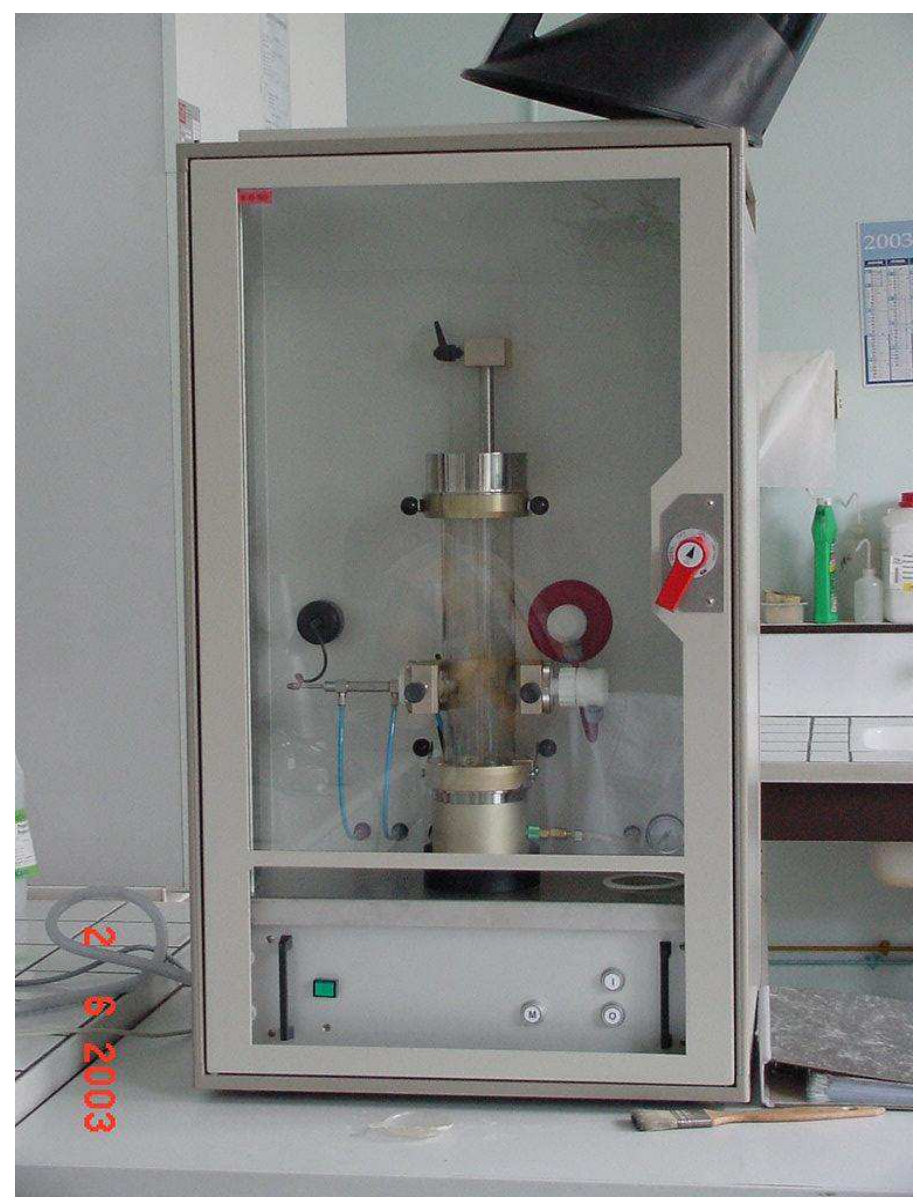

Figure 3: Front view of the MIKE 3 apparatus. 


\begin{tabular}{|c|c|c|}
\hline Energy range & Substances & Type (according to EN 13821 [5]) \\
\hline \multirow{5}{*}{$1 \mathrm{~mJ}-10 \mathrm{~mJ}$} & Sulphur powder & Natural mineral \\
\hline & Toner & Synthetic organic \\
\hline & Anthraquinone & Synthetic organic \\
\hline & $\begin{array}{l}\text { Niacin (pyridine-3-carboxamide) (sample } \\
\text { provided for the round robin tests CaRo 05) }\end{array}$ & Synthetic organic \\
\hline & Calcium stearate & Synthetic organic \\
\hline \multirow{7}{*}{$10 \mathrm{~mJ}-100 \mathrm{~mJ}$} & Lycopodium & Natural organic \\
\hline & Starch & Natural organic \\
\hline & Corn starch & Natural organic \\
\hline & Wood dust & Natural organic \\
\hline & Aluminum powder & Metal \\
\hline & Agroalimentary product 1 & Natural organic \\
\hline & Agroalimentary product 2 & Natural organic \\
\hline \multirow{6}{*}{$100 \mathrm{~mJ}-1 \mathrm{~J}$} & Aluminum dust & Metal \\
\hline & Crushed pea fiber & Natural organic \\
\hline & Cocoa & Natural organic \\
\hline & Atomised arabic gum & Natural organic \\
\hline & Coal dust & Coal \\
\hline & Pharmaceutical product & Synthetic organic \\
\hline
\end{tabular}

Table 2: List of substances tested in the study. Granulometry of aluminium powder is thinner than aluminium dust one. Classification in energy range is based on MIKE 3 results. 


\begin{tabular}{|c|c|c|c|}
\hline \multirow{2}{*}{ Energy range } & \multirow{2}{*}{ Substances } & \multicolumn{2}{|c|}{ Minimum Ignition Energy $(\mathrm{mJ})$} \\
\hline & & MIKE 3 & HARTMANN \\
\hline \multirow{5}{*}{$1 \mathrm{~mJ}-10 \mathrm{~mJ}$} & Sulphur powder & $1<\mathrm{MIE}<3$ & $4.5<\mathrm{MIE}<5.9$ \\
\hline & Toner & $1<\operatorname{MIE}<3$ & $7.6<\mathrm{MIE}<9.4$ \\
\hline & Anthraquinone & $1<\mathrm{MIE}<3$ & $7.6<\mathrm{MIE}<9.4$ \\
\hline & $\begin{array}{l}\text { Niacin (pyridine-3- } \\
\text { carboxamide) (sample } \\
\text { provided for the round robin } \\
\text { tests CaRo 05) }\end{array}$ & $1<\mathrm{MIE}<3$ & $12<\mathrm{MIE}<16$ \\
\hline & Calcium stearate & $3<\mathrm{MIE}<10$ & $7.6<\mathrm{MIE}<9.4$ \\
\hline \multirow{7}{*}{$10 \mathrm{~mJ}-100 \mathrm{~mJ}$} & Lycopodium & $10<\mathrm{MIE}<30$ & $12<\mathrm{MIE}<16$ \\
\hline & Starch & $30<\mathrm{MIE}<100$ & $27<\mathrm{MIE}<36$ \\
\hline & Corn starch & $30<\mathrm{MIE}<100$ & $45<\mathrm{MIE}<58$ \\
\hline & Wood dust & $30<\mathrm{MIE}<100$ & $45<\mathrm{MIE}<58$ \\
\hline & Aluminum powder & $30<\mathrm{MIE}<100$ & $45<\mathrm{MIE}<58$ \\
\hline & Agroalimentary product 1 & $30<\mathrm{MIE}<100$ & $77<\mathrm{MIE}<105$ \\
\hline & Agroalimentary product 2 & $30<\mathrm{MIE}<100$ & $105<$ MIE $<158$ \\
\hline \multirow{6}{*}{$100 \mathrm{~mJ}-1 \mathrm{~J}$} & Aluminum dust & $100<\mathrm{MIE}<300$ & $225<$ MIE $<360$ \\
\hline & Crushed pea fiber & $100<\mathrm{MIE}<300$ & $1100<\mathrm{MIE}$ \\
\hline & Cocoa & $300<\mathrm{MIE}<1000$ & $1100<\mathrm{MIE}$ \\
\hline & Atomised arabic gum & $300<\mathrm{MIE}<1000$ & $1100<\mathrm{MIE}$ \\
\hline & Coal dust & $1000<$ MIE & $1200<$ MIE \\
\hline & Pharmaceutical product & $1000<\mathrm{MIE}$ & $1200<\mathrm{MIE}$ \\
\hline
\end{tabular}

Table 3: Results of the comparison tests of MIE determination. Granulometry of aluminium powder is thinner than aluminium dust one. Classification in energy range is based on MIKE 3 results. 


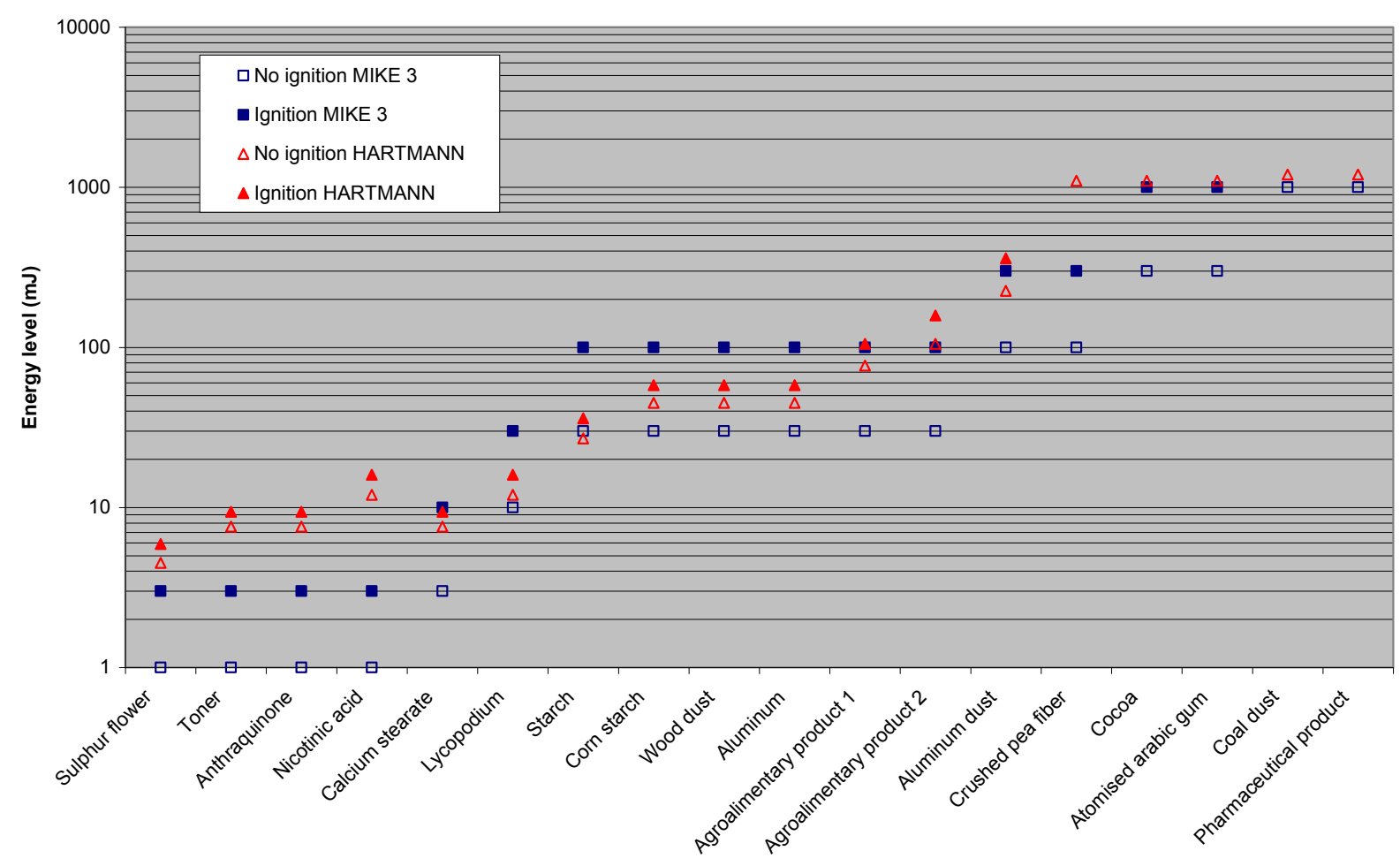

Figure 4: MIE measured results for tested substances with both explosion tubes. 


\begin{tabular}{|c|c|c|c|}
\hline \multirow{2}{*}{ Energy range } & \multirow{2}{*}{ Substances } & \multicolumn{2}{|c|}{ Sensitivity to electrostatic ignition sources } \\
\hline & & MIKE 3 & HARTMANN \\
\hline \multirow{5}{*}{$1 \mathrm{~mJ}-10 \mathrm{~mJ}$} & Sulphur powder & extremely sensitive & very sensitive \\
\hline & Toner & extremely sensitive & very sensitive \\
\hline & Anthraquinone & extremely sensitive & very sensitive \\
\hline & $\begin{array}{l}\text { Niacin (pyridine-3- } \\
\text { carboxamide) (sample } \\
\text { provided for the round robin } \\
\text { tests CaRo } 05 \text { ) }\end{array}$ & extremely sensitive & very sensitive \\
\hline & Calcium stearate & very sensitive & very sensitive \\
\hline \multirow{7}{*}{$10 \mathrm{~mJ}-100 \mathrm{~mJ}$} & Lycopodium & very sensitive & very sensitive \\
\hline & Starch & sensitive & very sensitive \\
\hline & Corn starch & sensitive & sensitive \\
\hline & Wood dust & sensitive & sensitive \\
\hline & Aluminum powder & sensitive & sensitive \\
\hline & Agroalimentary product 1 & sensitive & sensitive \\
\hline & Agroalimentary product 2 & sensitive & sensitive \\
\hline \multirow{6}{*}{$100 \mathrm{~mJ}-1 \mathrm{~J}$} & Aluminum dust & sensitive & sensitive \\
\hline & Crushed pea fiber & sensitive & Almost not sensitive \\
\hline & Cocoa & sensitive & Almost not sensitive \\
\hline & Atomised arabic gum & sensitive & Almost not sensitive \\
\hline & Coal dust & Almost not sensitive & Almost not sensitive \\
\hline & Pharmaceutical product & Almost not sensitive & Almost not sensitive \\
\hline
\end{tabular}

Table 4: Comparison of the sensitivity of tested samples to electrostatic ignition sources based on MIE measurement results. Granulometry of aluminium powder is thinner than aluminium dust one. Classification in energy range is based on MIKE 3 results. 


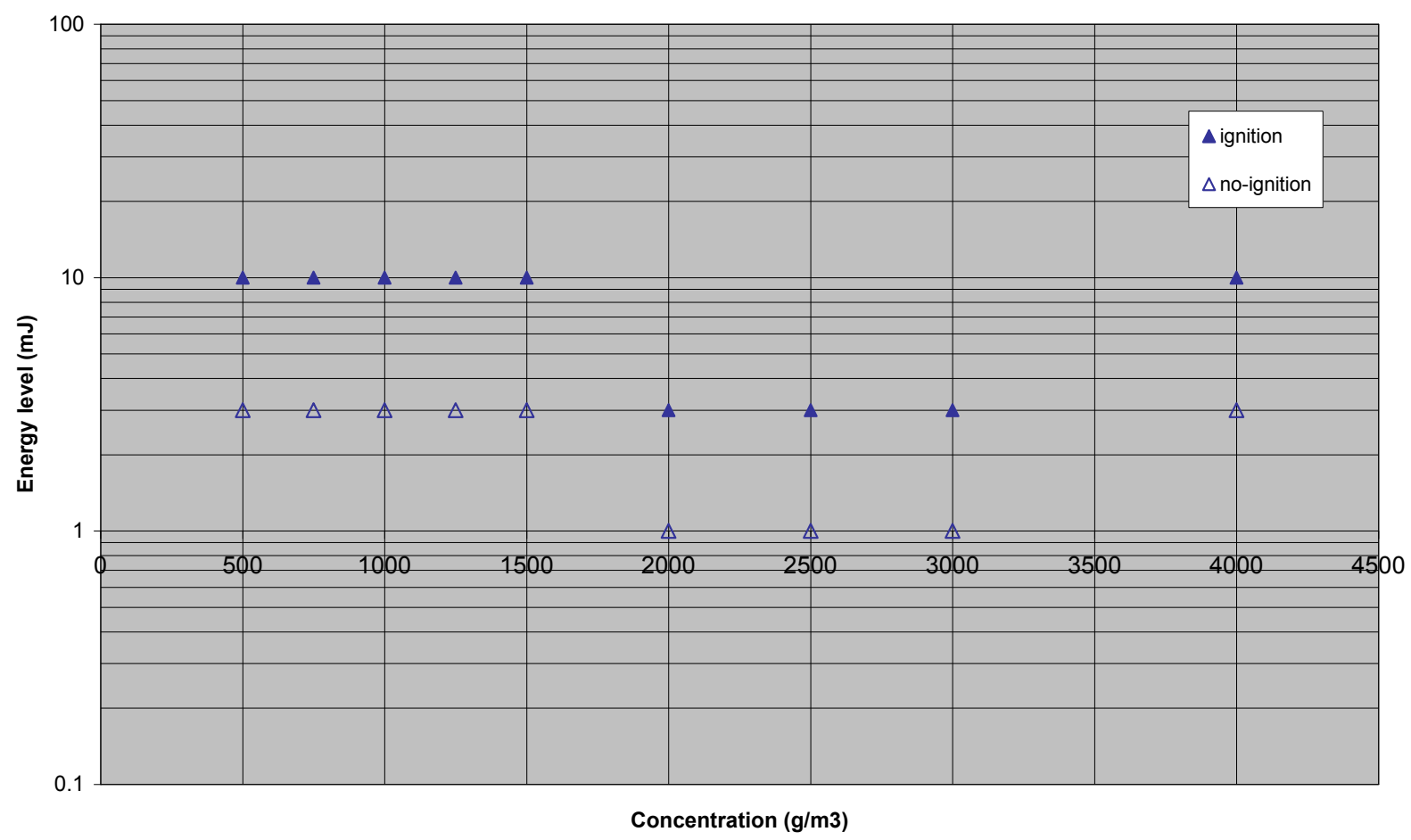

Figure 5: Evolution of MIE with average particle concentration for sulphur powder dust on MIKE 3 apparatus. Average particle concentration is based on the amount of dust placed in the bottom cup prior to the test and the volume of the explosion tube (delay between dispersion and sparkover: $180 \mathrm{~ms}$ ). 


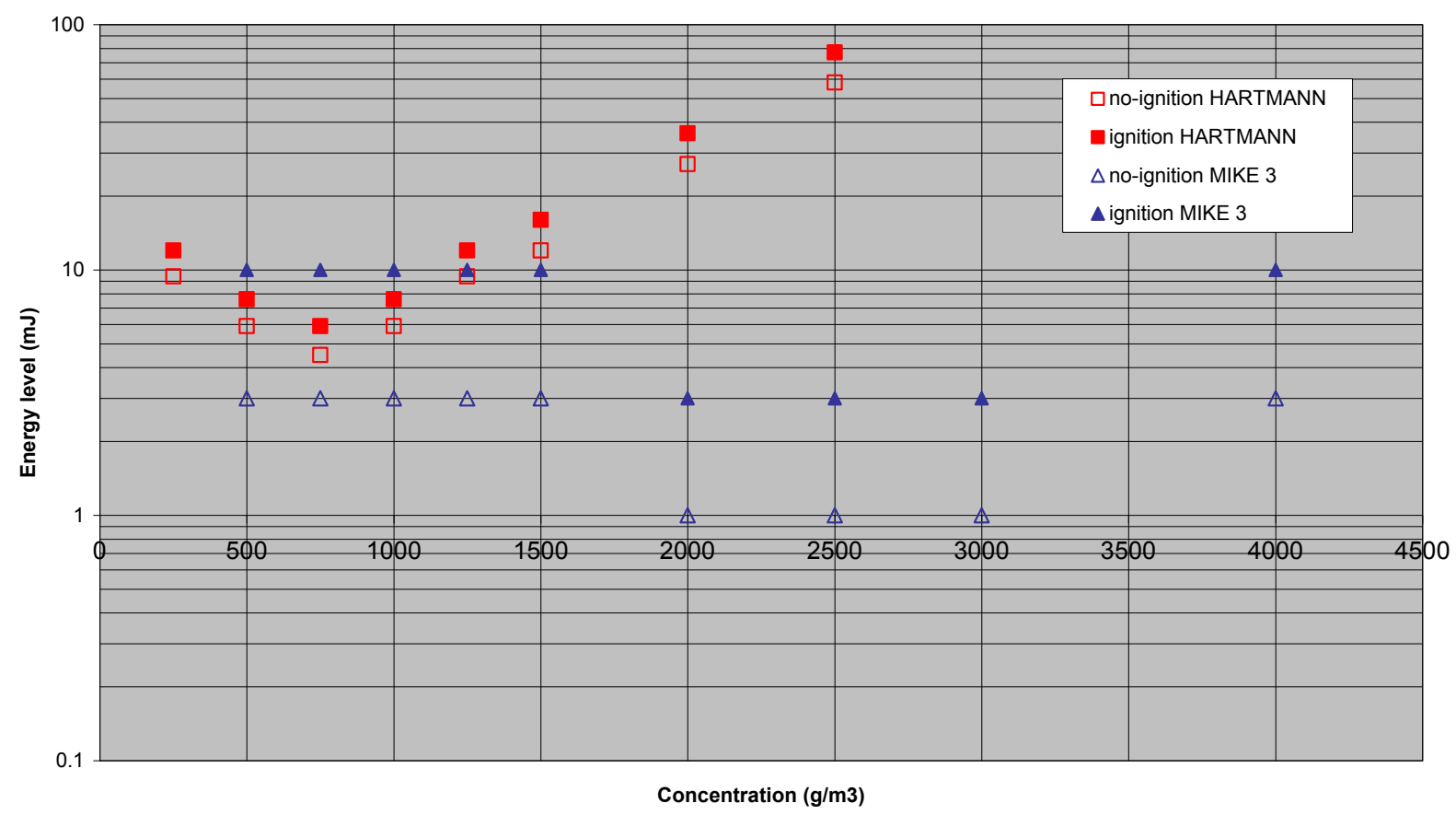

Figure 6: Comparison of MIE evolution with average particle concentration for sulphur powder on both MIKE 3 and HARTMANN explosion tubes. Average particle concentration is based on the amount of dust placed in the bottom cup prior to the test and the volume of the explosion tube (delay between dispersion and sparkover: MIKE 3: $180 \mathrm{~ms}$; HARTMANN: $300 \mathrm{~ms}$ ). 


\begin{tabular}{|c|c|c|}
\hline \multirow{2}{*}{ Substances } & \multicolumn{2}{|c|}{$\begin{array}{l}\text { Optimal average concentration range in explosion tube in } \mathrm{mg} / \mathrm{m}^{3} \\
\text { (optimal delay range between dust dispersion and sparkover in } \mathrm{ms} \text { ) }\end{array}$} \\
\hline & MIKE 3 & HARTMANN \\
\hline Sulphur powder & 2000 to $3000\left(180^{*}\right)$ & 750 (300 and 700) \\
\hline Toner & 500 to 750 (60 and 180$)$ & $1000(700)$ \\
\hline $\begin{array}{l}\text { Niacin (pyridine-3- } \\
\text { carboxamide) (sample } \\
\text { provided for the round } \\
\text { robin tests CaRo 05) }\end{array}$ & $\begin{array}{l}750 \text { to } 1000(120) \\
\text { and } 500 \text { to } 750(90)\end{array}$ & $500(300)$ \\
\hline Starch & $1250(60)$ & $2750-3250(300$ and 700$)$ \\
\hline Corn starch & $>900(120)$ & $1750-2000(300 *)$ \\
\hline Wood dust & 750 (60 and 180$)$ & 1000 (300 and 700) \\
\hline Aluminum powder & $>500(60$ and 180$)$ & 750 (300 and 700) \\
\hline Agroalimentary product 1 & $>1500(60$ and 180$)$ & $>500(300$ and 700$)$ \\
\hline Agroalimentary product 2 & 1250 (60 and 180) & > $1750(300$ and 700$)$ \\
\hline Aluminum dust & 1500 to 1750 (60 and 180$)$ & 1250 to $1750(300$ and 700$)$ \\
\hline
\end{tabular}

Table 5: Comparison of optimal concentration range for some substances on both MIKE 3 and HARTMANN explosion tubes. Granulometry of aluminium powder is thinner than aluminium dust one. Average particle concentration is based on the amount of dust placed in the bottom cup prior to the test and the volume of the explosion tube (*other delays not tested). 


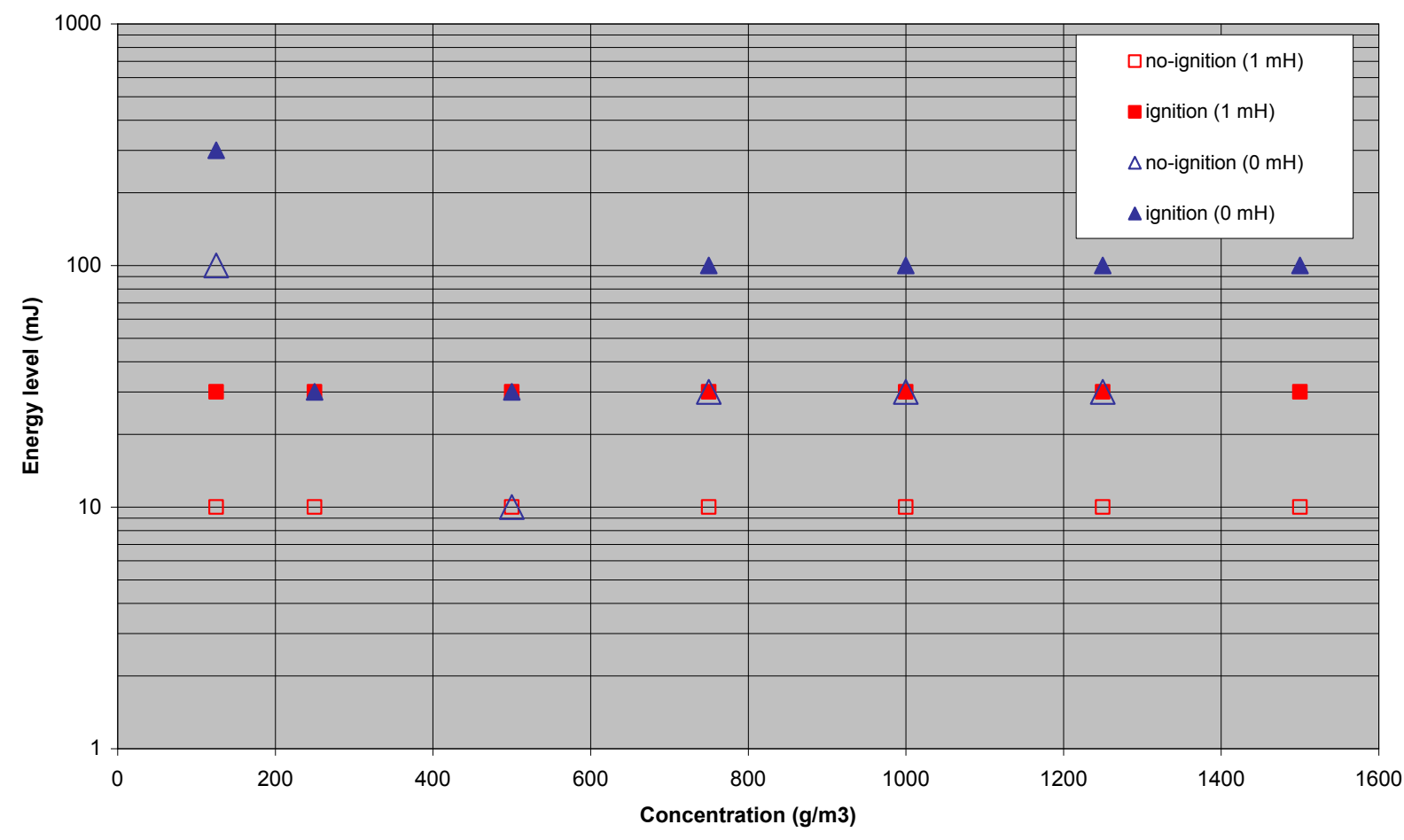

Figure 7: Comparison of MIE evolution with average particle concentration for lycopodium dust on MIKE 3 explosion tube with and without inductance. Average particle concentration is based on the amount of dust placed in the bottom cup prior to the test and the volume of the explosion tube (delay between dispersion and sparkover: $180 \mathrm{~ms}$ ). 